\title{
Autism-associated CHD8 deficiency impairs axon development and migration of cortical neurons
}

\author{
Qiong $X u^{1,3+}$, Yuan-yuan Liư ${ }^{2 \dagger}$, Xiaoming Wang ${ }^{3}$, Guo-he Tan², Hui-ping Li', Samuel W. Hulbert ${ }^{4}$, Chun-yang Li ${ }^{1}$, \\ Chun-chun $\mathrm{Hu}^{1}$, Zhi-qi Xiong ${ }^{5,6}$, Xiu Xu ${ }^{1 *}$ and Yong-hui Jiang $3,4,7,8^{*}$
}

\begin{abstract}
Background: Mutations in CHD8, chromodomain helicase DNA-binding protein 8, are among the most replicated and common findings in genetic studies of autism spectrum disorder (ASD). The CHD8 protein is believed to act as a transcriptional regulator by remodeling chromatin structure and recruiting histone $\mathrm{H} 1$ to target genes. The mechanism by which deficiency of CHD8 causes ASD has not been fully elucidated.

Methods: We examined the expression of CHD8 in human and mouse brains using both immunohistochemistry and RNA in situ hybridization. We performed in utero electroporation, neuronal culture, and biochemical analysis using RNAi to examine the functional consequences of CHD8 deficiency.

Results: We discovered that CHD8 is expressed highly in neurons and at low levels in glia cells in both humans and mice. Specifically, CHD8 is localized predominately in the nucleus of both MAP2 and parvalbumin-positive neurons. In the developing mouse brain, expression of Chd8 peaks from E16 to E18 and then decreases significantly at P14 to adulthood. Knockdown of Chd8 results in reduced axon and dendritic growth, disruption of axon projections to the contralateral cortex, and delayed neuronal migration at E18.5 which recovers by P3 and P7.

Conclusion: Our findings indicate an important role for CHD8 in dendritic and axon development and neuronal migration and thus offer novel insights to further dissect the underlying molecular and circuit mechanisms of ASD caused by CHD8 deficiency.
\end{abstract}

Keywords: CHD8, Autism spectrum disorder (ASD), Chromatin remodeling, Neurite growth, Neurodevelopment

\section{Background}

Autism spectrum disorder (ASD) is a group of clinically and molecularly heterogeneous neurodevelopmental conditions characterized by social communication deficits and restricted, repetitive behaviors [1,2]. Genetic etiology has been implicated in approximately $20 \%$ of ASD patients. More than 70 genes or genomic loci have been confirmed as causative, and hundreds are considered strong candidates [3-12]. Of these, mutations in

\footnotetext{
* Correspondence: xuxiu@fudan.edu.cn; yong-hui.jiang@duke.edu ${ }^{\dagger}$ Qiong Xu and Yuan-yuan Liu contributed equally to this work.

'Department of Child Health Care, Children's Hospital of Fudan University, Shanghai 201102, China

${ }^{3}$ Department of Pediatrics, Duke University School of Medicine, Durham 27710, NC, USA

Full list of author information is available at the end of the article
}

CHD8 are among the most replicated and commonly identified genetic findings $[6,7,13,14]$.

CHD8 is a member of the chromodomain helicase DNA-binding protein family, which functions as an ATP-dependent chromatin remodeling factor and plays important roles in chromatin dynamics, transcription, and cell survival [15]. CHD8 is initially identified as a negative regulator of the Wnt-catenin signaling pathway through promoting the association of $\beta$-catenin and histone $\mathrm{H} 1$ and forming a trimeric complex on chromatin [16-18]. Accordingly, Wnt- $\beta$-catenin signaling was downregulated in Chd8 mutant mice [18]. Homozygous deletion of $C h d 8$ in mice results in early embryonic lethality as a consequence of massive apoptosis in some lines of mutant mice [19, 20]. Haploinsufficiency of CHD8 causes abnormal activation of RE-1 silencing

(C) The Author(s). 2018 Open Access This article is distributed under the terms of the Creative Commons Attribution 4.0 International License (http://creativecommons.org/licenses/by/4.0/), which permits unrestricted use, distribution, and 
transcription factor (REST), which suppresses the transcription of many neuronal genes. Moreover, CHD8 interacts physically with REST in the mouse brain [21]. Knockdown of Chd8 by RNAi during cortical development results in defective neural progenitor proliferation, differentiation, and enhanced migration $[18,22]$. Deficiency of $C h d 8$ in mice also alters synaptic transmission in striatal circuitry and results in functional over-connectivity in cortical networks [23]. Interestingly, a recent report also shows sexually dimorphic phenotypes related to abnormal neuronal excitation, enhanced inhibitory synaptic transmission and neuronal firing, and gene dysregulation in a new line of Chd8 mutant mice [24]. Conditional knockout of $C h d 8$ in oligodendrocytes results in defective myelination in mice [25]. However, whether CHD8 deficiency affects axonal growth has not been studied.

Here, we report that CHD8 is specifically expressed in both excitatory and inhibitory neurons and to a lesser extent in GFAP+ astrocytes of cerebral cortex in human and mouse brains. Similar to a previous report, we found that the expression of Chd8 peaks during embryonic development and decreases to relatively low levels postnatally in mouse brains [22]. Chd 8 deficiency in neocortex by RNAi using in utero electroporation resulted in delayed migration of cortical neurons and impaired dendritic and axonal growth. Our findings provide additional insights into the molecular and circuitry mechanisms underlying ASD caused by CHD8 deficiency. Defective axonal development may support a mechanism underlying the abnormal long distance connectivity reported in neuroimaging studies of ASD in humans.

\section{Methods}

\section{Immunostaining of human brain sections}

For light microscopic immunohistochemistry (IHC), human brain sections $(30 \mu \mathrm{m})$ were incubated in $0.01 \mathrm{M}$ phosphate-buffered saline (PBS) supplemented with 3\% hydrogen peroxide for 10 min to block endogenous peroxidase and then in a blocking buffer containing 5\% BSA $/ 10 \%$ normal goat serum $/ 0.25 \%$ Triton X-100 for 60 $\mathrm{min}$ at room temperature to prevent nonspecific staining. Following this, IHC was conducted on these free-floating sections and staining was visualized with a standard ABC Elite kit (Vector Labs).

For confocal microscopic double-labeling immunofluorescence, brain sections were incubated in the blocking buffer for $60 \mathrm{~min}$ at room temperature and then in a solution containing primary antibodies from different species simultaneously for one night at $4{ }^{\circ} \mathrm{C}$. After washing, sections were incubated with appropriate secondary antibodies from Alexa Fluor series (Invitrogen, USA) for $45 \mathrm{~min}$ at $37^{\circ} \mathrm{C}$ and then counterstained with Hoechst 33342 (1:5000; \#C10022, Beyotime) for $15 \mathrm{~min}$ at room temperature to identify cellular nuclei. After mounting the sections, we observed them under a fluorescent confocal microscope (A1R Nikon).

Primary antibodies used were as follows: anti-CHD8 (1: 500; catalog \#A301-225A; Bethyl Laboratories, Inc.), anti-GFAP (1:1000, catalog \#MAB3402, Millipore), antiMAP2 (1:2000, catalog \#M9942, Sigma), anti-parvalbumin (Pvalb) (1:500, catalog \#MAB1572, Millipore), and anti-DCX antibodies (1:200, catalog \#Sc-8066, Santa Cruz).

For Nissl staining, Neuro Trace 500/525 green fluorescent Nissl stain (N21480) was bought from Thermo Fisher Scientific and used according to the manufacture's instruction.

\section{Confocal microscopic double-labeling} immunofluorescence of mouse brain slices

Mice were sacrificed by cervical dislocation at postnatal day 3 (P3) or P7. Their brains were removed and fixed in $4 \%(\mathrm{wt} / \mathrm{vol})$ paraformaldehyde (PFA) overnight. After sequential dehydration in $15 \%$ and $30 \%$ sucrose at $4{ }^{\circ} \mathrm{C}$, $50-\mu \mathrm{m}$ coronal brain sections were cut with a cryostat, fixed in $4 \%$ PFA for $20 \mathrm{~min}$ at $4{ }^{\circ} \mathrm{C}$, washed three times with PBS, blocked with 5\% BSA and 0.3\% Triton X-100 in PBS for $1 \mathrm{~h}$ at room temperature, and then incubated with rabbit anti-GFP (1:1000, catalog \#A11122, Invitrogen) primary antibody overnight at $4{ }^{\circ} \mathrm{C}$. The rinsed sections were then incubated with Alexa 488-conjugated goat anti-rabbit secondary antibody (1:3000; catalog \#A-11122; Invitrogen) for $2 \mathrm{~h}$ at $37^{\circ} \mathrm{C}$. For endogenous CHD8 and NeuN immunostaining, sections were incubated with anti-CHD8 antibody (1: 500; catalog \#A301225A; Bethyl Laboratories, Inc.) and anti-NeuN antibody (1:500; catalog \# MAB377; Millipore).

Cultured neurons were fixed with 4\%PFA and then immunostained with primary antibodies against GFAP (1:1000, catalog \#MAB3402, Millipore), MAP2 (1:2000, catalog \#M9942, Sigma), and Tau1 (1:3000, catalog \#MAB3420, Millipore) overnight at $4{ }^{\circ} \mathrm{C}$. After washing, sections were then incubated with Alexa 488-conjugated goat anti-rabbit secondary antibody (1:3000, catalog \#A-11122, Invitrogen) and Alexa 568-conjugated goat anti-mouse secondary antibody (1:2000, catalog \#A-11004, Invitrogen) for $2 \mathrm{~h}$ at $37^{\circ} \mathrm{C}$.

\section{RNA extraction and real-time PCR}

Forebrain tissues from embryonic or postnatal mice $(\mathrm{C} 57 \mathrm{BL} / 6)$ at different developmental stages (E16, E18, P0, P7, P14, P21, and adult) were used for RNA extraction. Mice were anesthetized with sodium pentobarbital and sacrificed via cervical dislocation, and brain tissues were quickly removed, dissected on ice, and homogenized with TRIzol Reagent (Invitrogen) at $4{ }^{\circ} \mathrm{C}$. RNA was extracted according to the recommendations of the manufacturer, the final RNA pellet was suspended in 
diethylpyrocarbonate (DEPC)-treated water, and $2 \mu \mathrm{g}$ of total mRNA was further subjected to reverse transcription using oligo (dT) primers and Moloney murine leukemia virus (M-MLV) transcriptase (Invitrogen). Real-time PCR was done with a LightCycler 480 Real-Time PCR System (Roche) according to the manufacturer's instructions. Starting RNA levels were quantified by using GAPDH as the external standard. Primer sets were chosen from Primerbank, and gene sequences are available from the GenBank database. The primer sequences to examine the mRNA expression of mouse Chd8 were as follows: forward, 5'-AAGCCCAGGTAACTCAAC-3'; reverse, 5'-TTCACATCGTCGGCGTCT-3'; GAPDH: forward, 5'-GGTTGTCTCCTGCGACTTCA-3'; reverse, 5'-CCACCACCCTGTTGCTGTAG-3'. The primers were synthesized by Invitrogen.

\section{RNA in situ hybridization}

RNA in situ hybridization on the mouse brain sections was performed with digoxigenin (DIG)-labeled RNA probes. Full-length cDNA of Chd8 was amplified with specific PCR primers and cloned into a pGEM-T easy vector (Promega) to generate an antisense probe for Chd8. The DIG-labeled antisense probes were synthesized by in vitro transcription using SP6 RNA polymerase. Mice of different developmental stages were perfused with $4 \%$ PFA, and fixed brains were sectioned into $20-\mu \mathrm{m}$ slices using a cryostat. RNA in situ hybridization was performed as described previously [26]. Brain sections were hybridized for $18 \mathrm{~h}$ at $60^{\circ} \mathrm{C}$. The hybridization signal was detected with anti-DIG-alkaline phosphatase Fab fragments (Roche) and nitro blue tetrazolium chloride (NBT) plus 5-bromo-4-chlor-indolyl-phosphate (BCIP) as color reaction substrates.

\section{Human CHD8 cloning and mouse shRNA construct preparation}

Human CHD8 cDNA (CHD8, variant 1 - HaloTag ${ }^{\circ}$ human ORF in pFN21A) was purchased by Promega (catalog: FHC12740). PCR products were cloned into the pCAGGS-IRES-EGFP vector [27]. Oligonucleotides targeting different sequences of mouse Chd8 cDNA and a scrambled control oligonucleotide were designed, synthesized, and cloned into pSuper-basic (Oligoengine). The 21-bp target sequences were as follows: shRNA\#1, 5'-GCT GGT GGA CTT GGT ATT AAT-3'; shRNA\#2, 5'-GCT GCT GAT ACC TGT ATT ATC-3'; shRNA\#3, 5'-GCT ACA AGA GAG AAC AAA TGA-3'; and shRNA-scramble, 5'-TTC TCC GAA CGT GTC ACG T-3'. All constructs were verified by DNA sequencing.

\section{Western blot analysis}

For the analysis of the expression of CHD8 in the developing mouse cortex, cortices were dissected and homogenized as previously described [28]. For knockdown and rescue experiments, electroporated cortical neurons were cultured for 3-7 days and lysed in $1 \times$ protein loading buffer (50 mM Tris-HCl, pH 6.8, 2\% SDS, 10\% glycerol, $1 \%$ 2-ME, and $0.1 \%$ bromophenol blue). All protein samples were separated by $10 \%$ SDS-polyacrylamide gel electrophoresis (Bio-Rad) and blotted onto PVDF membrane (Millipore). Membranes were blocked with 5\% non-fat milk in $0.05 \%$ Tween 20 at room temperature for $1 \mathrm{~h}$ and probed with rabbit anti-CHD8 (Bethyl Laboratories, Inc.), HRP-coupled mouse anti-actin (Santa Cruz Biotechnology) antibodies. The secondary antibody used for CHD8 was goat anti-rabbit IgG coupled to HRP (Santa Cruz biotechnology). Bands were visualized by enhanced chemiluminescence (TIANGEN). Band intensities were measured with ImageJ Software.

\section{Primary neuron culture and electroporation}

Primary cortical neurons were prepared from brains of P0 C57 mice as described previously [28]. Before plating, neurons suspended in transfection medium $(200 \mu \mathrm{l})$ were mixed with $1 \mu \mathrm{g}$ pCAG-EGFP and $3 \mu \mathrm{g}$ shRNA for immunocytochemistry. Then, neurons were transferred into a 2.0-mm electroporation cuvette (Fisher) and transfected by electroporation using the Amaxa Nucleofector apparatus.

\section{In utero electroporation}

In utero electroporation was performed as described previously with a few modifications [27]. Briefly, pregnant mice at E14.5 were anesthetized with $0.7 \%$ sodium pentobarbital at a dose of $10 \mu \mathrm{l} / \mathrm{g}$ and subjected to abdominal incision to expose the uterus. For different experiments, a mixture of GFP, RNAi, and/or rescue constructs was prepared. Plasmids (about $1 \mu \mathrm{l}$ ) with 0.05\% Fast Green (Sigma) were injected into the lateral ventricle of embryos through a glass micropipette. Electrical pulses were then delivered to embryos by gently clasping their heads with forcep-shaped electrodes connected to an ECM-830 square-pulse generator (BTX). Five 50-ms pulses of $30 \mathrm{~V}$ were applied at 1-s intervals. Uterine horns were repositioned in the abdominal cavity, and the abdominal wall and the skin were sutured. Postsurgery animals were maintained in a warm animal room $\left(25^{\circ} \mathrm{C}\right)$ with plenty of water and food. At different developmental stages, mice were perfused transcardially with $0.9 \%$ saline followed by $4 \%$ PFA in $0.1 \mathrm{M}$ phosphate buffer (PB; $\mathrm{pH} 7.4$ ), and the brains were removed and fixed in 4\% PFA for another $24 \mathrm{~h}$. Fixed brains were cryoprotected with $30 \%$ sucrose and then sectioned using a cryostat.

\section{Image acquisition and quantification}

Images were obtained with a Nikon A1R inverted confocal microscope with $\times 20$ (numerical aperture, 0.7) 
objectives. Each image was a composite constructed from a series of images taken throughout the $z$ aspect of the neuron. Images of isolated cells or cortical neurons in regions with a low density of GFP transfected cells were chosen for illustration, and three-dimensional (3D) reconstructions were made to trace dendritic or axonal arbors for measurement of total dendritic or axonal length. Neurolucida software (MBF Bioscience) was used to generate tracings to measure neurite lengths. Sholl analysis, a quantitative analysis by counting the number of neurite intersections of concentric circles of gradually increased radius centered at the cell body, was performed with Neurolucida Explorer (MBF Bioscience). Image acquisition and data analysis were performed in a double-blind manner.

\section{Statistical analysis}

For all statistical analyses, experimenters were blinded for genotypes of mice and the treatments of the animals or cells. Data are presented as mean \pm SEM. The paired or unpaired Student's $t$ test, one-way ANOVA with Dunnett's post hoc tests or Bonferroni's tests, or two-way ANOVA with Bonferroni post hoc tests were used for data analyses by SPSS 13.0 software. Statistical significance was defined as $P<0.05$.

\section{Animals}

Except in utero electroporation, for which ICR mice were used, all other experiments were performed in C57BL/6 J mice. Pregnant mice undergoing in utero electroporation were individually housed in plastic cages, and when they delivered, they were housed with their pups.

\section{Human brain tissues}

Frozen postmortem brain tissues of Brodmann 19 region from a 6-year-old child was obtained from the $\mathrm{NIH}$ human brain tissue bank at the University of Maryland (http://www.medschool.umaryland.edu/btbank/). The postmortem time was $19 \mathrm{~h}$.

\section{Results \\ CHD8 is predominantly expressed in neurons of human cerebral cortex}

To probe the function of CHD8 and its pathophysiology underlying ASD, we first examined the expression pattern of CHD8 in a human brain sample. We performed immunohistological analysis using postmortem brain tissue (Brodmann 19) of a 6-year-old child. Strong staining of CHD8 was revealed in cerebral cortex (Fig. 1a). CHD8 was highly expressed in Neuro Trace Nissl stain-positive neurons but to a lesser extent in GFAP-positive glia cells (Fig. 1b, c). Consistent with the known function of CHD8 as a chromatin regulator, immunofluorescent staining showed that CHD8 was predominantly localized in the nucleus (Fig. 1b, f). Co-staining of CHD8 and neuronal markers showed that CHD8 was expressed in both MAP2-positive excitatory neurons (Fig. 1d) and parvalbumin (Pvalb)-positive interneurons (Fig. 1e). Moreover, CHD8 was expressed in Doublecortin (DCX)-positive neuronal precursor cells and immature neurons (Fig. 1f), which is consistent with the early onset of clinical manifestations in patients with CHD8 mutations.

\section{Chd8 is highly expressed in the developing mouse brain} Next, we examined the expression pattern of $C h d 8$ in the mouse brain at different developmental stages. Quantitative real-time mRNA expression analysis (qRT-PCR) (Fig. 2a) revealed that Chd8 was detectable in neocortex from E16 to adulthood. The peak of the expression is at E18 and then markedly decreases at P7 and gradually declines to very low levels at adulthood. This expression pattern in neocortex was also confirmed at the protein level by western blot analysis (Fig. 2b, c). To examine the temporal and spatial expression pattern of Chd8 in the developing brain, we performed RNA in situ hybridization on mouse brain sections. Chd8 mRNA was most abundant in embryonic brain and then gradually reduced after birth, consistent with the results from the qRT-PCR and western blot analyses. Specifically, Chd8 mRNA was present in the sub-plate (SP) and proliferative zones of the cortical wall (the ventricular zone [VZ] and the subventricular zone [SVZ]) at E16 and $\mathrm{PO}$ and in the cortical plate $(\mathrm{CP})$ of the cerebral cortex, hippocampus, striatum, cerebellum, and olfactory bulb from P3 to P7, a developmental period with extensive outgrowth and elaboration of dendrites and axons (Fig. 2d, e). The cellular and subcellular localizations of CHD8 in developing mouse brains and cultured neurons were also examined by immunostaining with neuronal cell markers. Consistent with the results in human cerebral cortex, mouse CHD8 was expressed in the neuronal nucleus, with a pattern similar to that of NeuN in neocortex and hippocampus in P3 mouse (Fig. 3a-c). CHD8 expression in neurons and glia cells was also confirmed by western blot analysis of cultured DIV3 neurons and glia cells of mice (Fig. 3d). However, the expression of CHD8 in glia cells was significantly lower than that in neurons. Taken together, the expression analyses of both human and mouse brains imply important roles for CHD8 during the development of cerebral cortex.

\section{CHD8 regulates neuronal morphogenesis in vitro}

Altered short- and long-distance functional connectivity has been reported frequently in brains of human ASD patients by neuroimaging studies [29, 30]. Impaired dendritic development has been reported in numerous mouse models of ASD [31-33]. However, few studies have examined axonal development in ASD animal models. We 

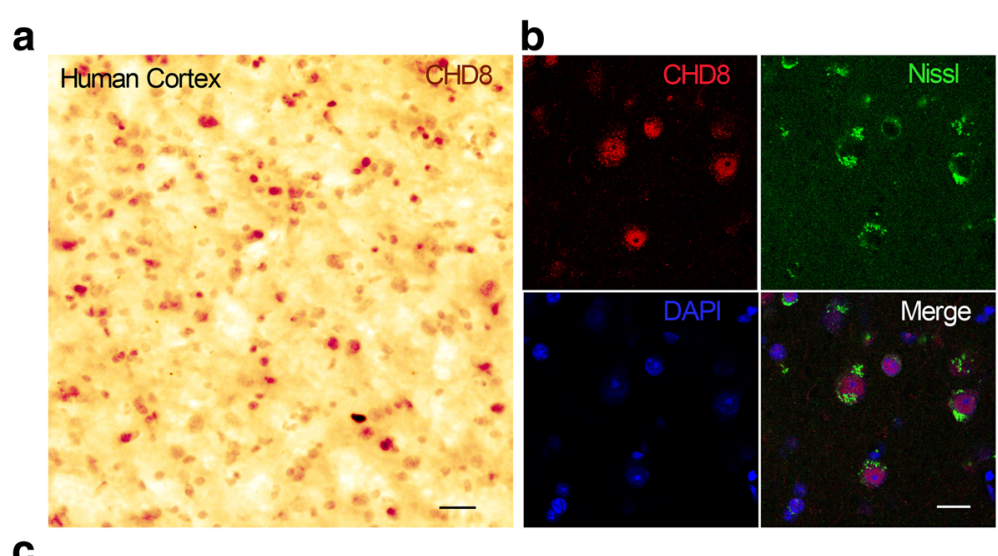

C

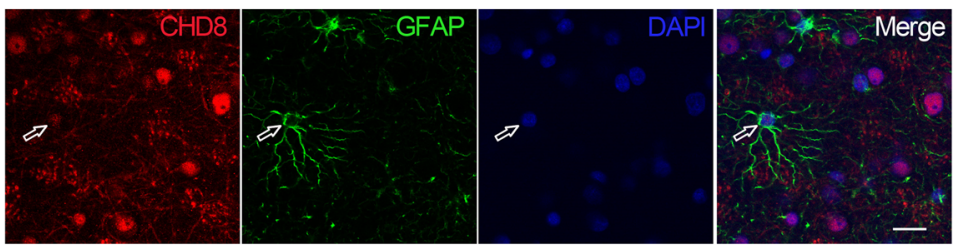

d

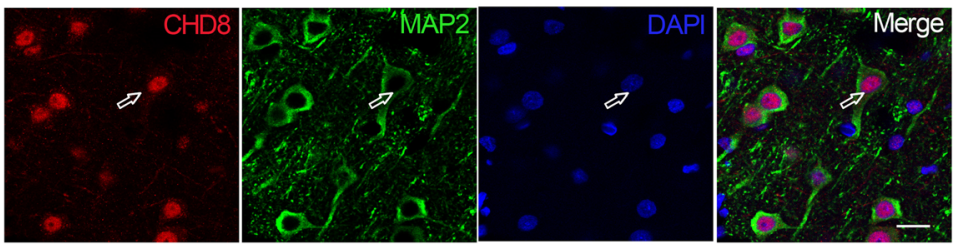

e

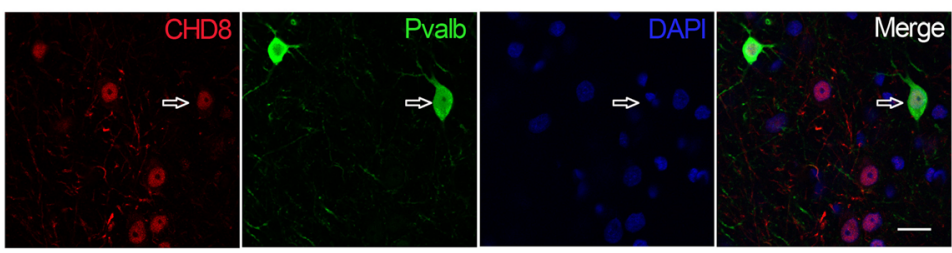

$\mathbf{f}$

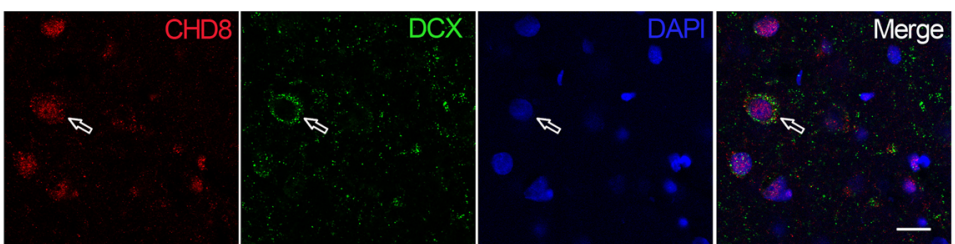

Fig. 1 Expression of CHD8 in human cerebral cortex. a Immunohistochemical staining revealed the expression pattern of CHD8 in human cerebral cortex from Brodmann 19 region. b Human CHD8 is expressed in neurons. The sections were immunostained with CHD8 antibody and counterstained with NeuroTrace 500/525 green fluorescent Nissl (Thermo Fisher Scientific). c CHD8 is expressed in GFAP+ astrocytes (open arrows: astrocytes). d CHD8 is expressed in MAP2-positive neurons (open arrows for MAP2 positive neurons). e CHD8 is expressed in pavalbumin (Pvalb)-positive interneurons (open arrows for Pvab-positive interneuron). $\mathbf{f}$ CHD8 is expressed in DCX-positive neurons (open arrows for DCX+ neuron) (scale bar, $20 \mu \mathrm{m}$ )

therefore examined whether Chd8 deficiency affects the development of both dendritic morphology and callosal axon growth during development using a shRNA approach. We designed three shRNA constructs that were targeting to Chd8 and tested the efficiency in both cultured neurons and in vivo in mouse brains. Compared with the scramble shRNA construct, all shRNAs resulted in a significant decrease in the expression of CHD8 protein in cultured neurons, and among them, shRNA\#1 had the highest efficiency (Fig. 4a). The efficacy of the shRNA constructs was confirmed in vivo in mouse brain (Fig. 4b). We also validated the rescued constructs against shRNA-mediated knockdown of mouse Chd8 in transfected neurons in vitro (Additional file 1: Figure S1). To examine axonal growth, we co-transfected dissociated DIV0 mouse cortical neurons with plasmids encoding 


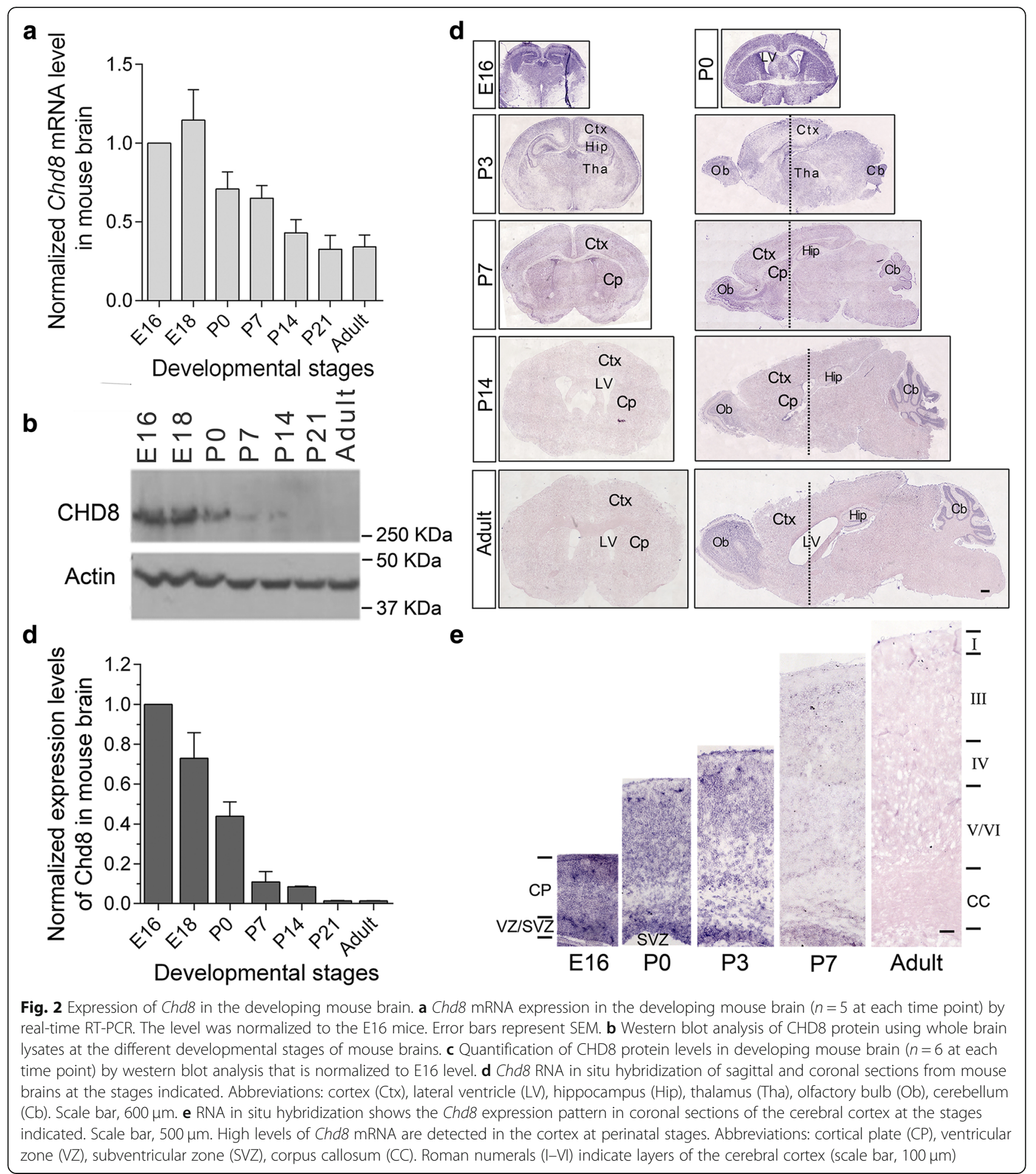

GFP and shRNA constructs by electroporation and then plated them to allow the neurons to grow in culture medium for 3 days (DIV3). We used Tau1 as an axon-specific marker. We found that depleting CHD8 significantly decreased total axon growth (Fig. 4c, d). However, co-expression of human CHD8 protein (hCHD8) that is shRNA\#2-resistant was able to rescue the total axon length defects caused by shRNA\#2 construct (Fig. 4c-e; Additional file 1: Figure S1). We next examined the effects of Chd8 knockdown on dendritic outgrowth and branching in vitro. Control neurons were transfected at DIV0 with GFP plus a non-targeting shRNA construct 


\section{a}

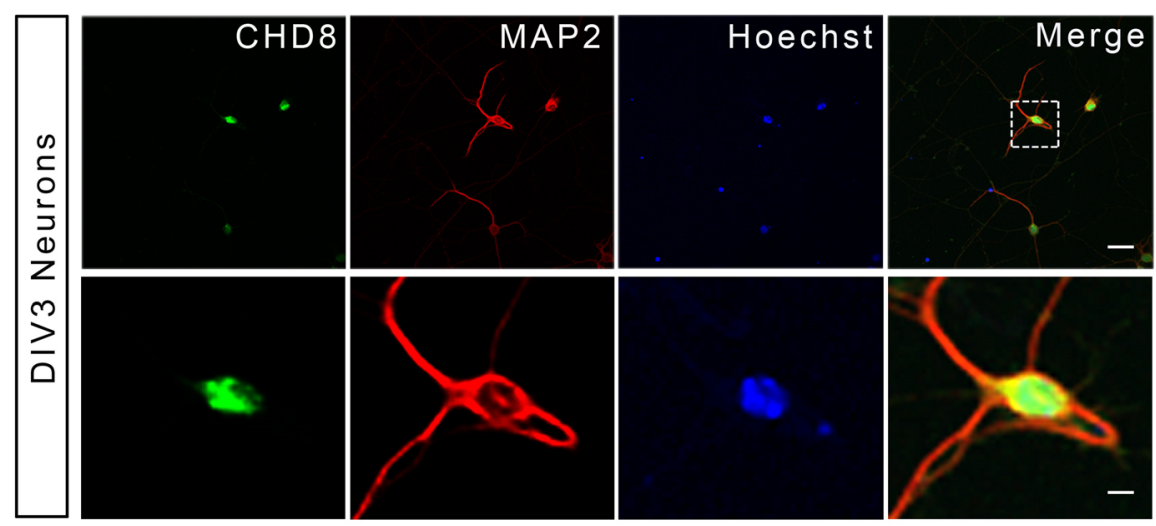

b

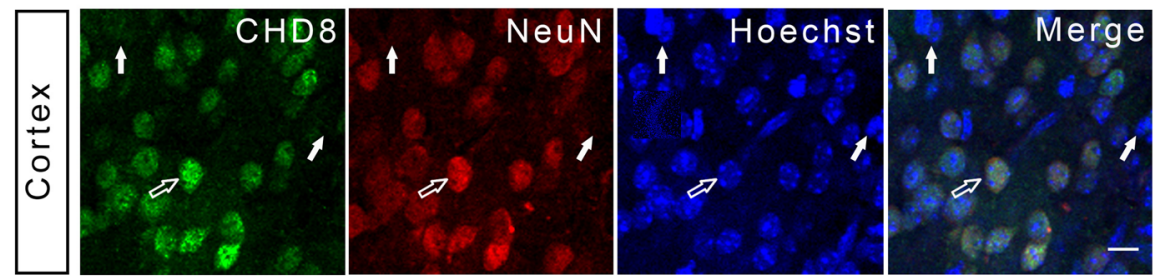

C

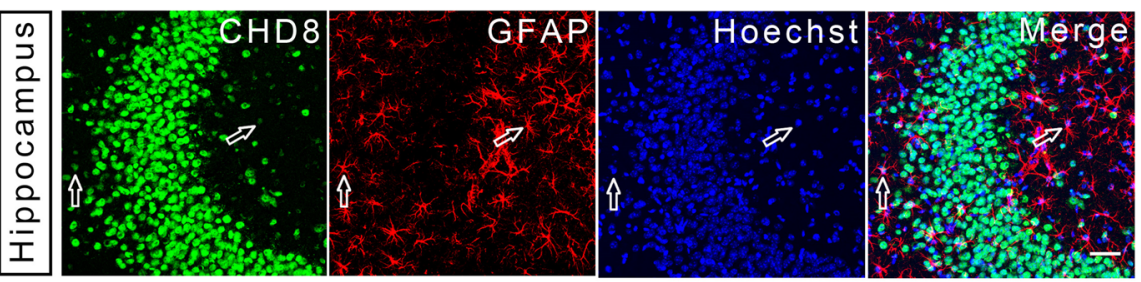

d

Neuron Glia

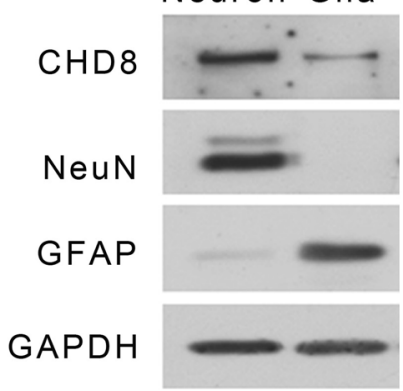

Fig. 3 Cell type-specific expression pattern of CHD8 in mouse brains. a Endogenous mouse CHD8 is selectively enriched in the nucleus of cultured DIV3 cortical neurons. Cells were immunolabeled with CHD8 (green), the somatodendritic marker MAP2 (red), and with counterstaining of nuclear marker Hoechst (blue). Scale bar, $2 \mu \mathrm{m}$. b Double-immunofluorescent staining shows that CHD8 is highly expressed in NeuN-positive neurons. Scale bar, $5 \mu m$. The open arrows indicate both CHD8 and NeuN-positive neurons, while the filled arrows indicate neither CHD8 nor NeuN-positive non-neuronal cells. c Double-immunofluorescent staining shows that CHD8 is weakly expressed in GFAP-positive astrocytes. The open arrows indicate GFAP-positive astrocytes with weak CHD8 expression. Scale bar, $25 \mu \mathrm{m}$. d Representative western blot shows that CHD8 is predominately expressed in neurons but also in cultured glia cells

(shRNA-scr). Seven days later, we analyzed the data after staining cells with the somatodendritic marker MAP2 (Fig. 4f). The total and mean dendrite length were significantly reduced in neurons expressing both shRNA\# 1 and shRNA\# 2 constructs compared to those expressing shRNA-scr (Fig. 4g). It is worth noting that the intersections were more affected by shRNA\#1 construct than by shRNA\#2 construct (Fig. 4h). This appears to be consistent with the more significant reduction of Chd8 after shRNA\# 1 treatment than that of shRNA\#2. The effects of shRNA\#2 were rescued by co-transfecting shRNA2-resistant hCHD8 (Fig. 4i, j). These results indicate CHD8 is required for both axonal and dendritic development. 


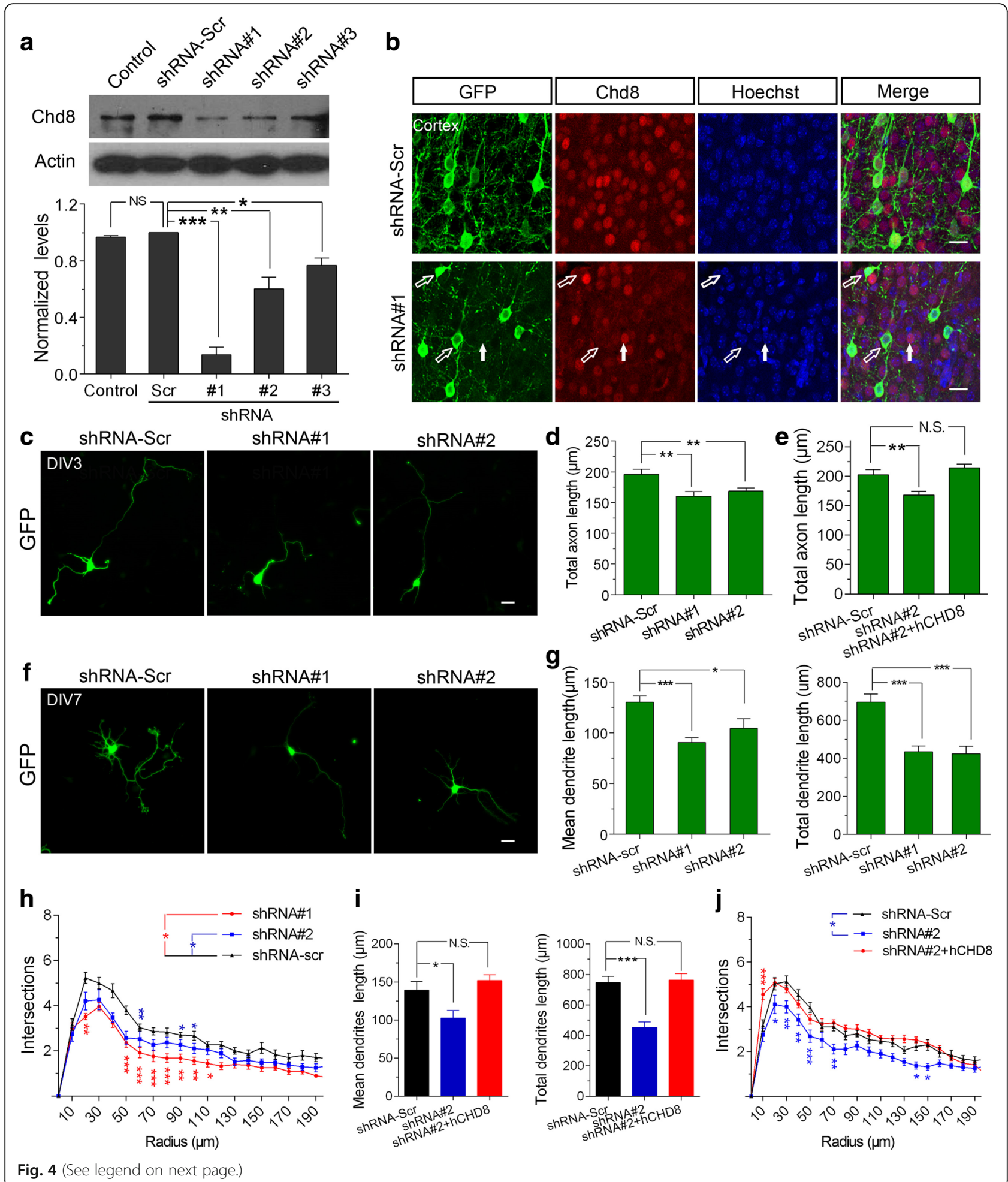




\section{(See figure on previous page.)}

Fig. 4 CHD8 regulates neurite growth in vitro. a shRNA-mediated knockdown of mouse Chd8 in transfected cultured neurons. Upper, representative western blots; lower, quantification of western blot analysis. shRNA\#1, $0.14 \pm 0.095$; shRNA\#2, $0.60 \pm 0.14$; shRNA\#1, $0.77 \pm 0.089$. For ANOVA, $P=0.587$. For post hoc Dunnets' test, ${ }^{* *} P=0.004$ for shRNA\#1 vs shRNA-scr; ${ }^{*} P=0.041$ for shRNA\#2 vs shRNA-scr; ${ }^{*} P=0.046$ for shRNA\#3 vs shRNA-scr. All data were shown in mean \pm SEM and were collected from three to six independent experiments. $\mathbf{b}$ Immunostaining showing shRNA-mediated knockdown of Chd8 in transfected neurons in mouse brains. Immunohistochemical staining of endogenous CHD8 in coronal sections from a P0 mouse brain electroporated with shRNA\#1 and GFP at E14.5. The open arrows indicate successfully transfected cells, and the filled arrows indicate normal cells. Scale bar, $10 \mu m$. c Representative images of DIV3 cultured neurons transfected with GFP and the plasmids indicated. Constructs were transfected at DIV0, cultured for 3 days in vitro, and then immunolabeled with anti-GFP. Scale bar, $100 \mu \mathrm{m}$. d Quantification of the total axon length of neurons transfected with Chd8 shRNA constructs. $n=126,133,124$ neurons per group, respectively. Total axon length: shRNA-scr, $196.0 \pm 8.42 \mu \mathrm{m} ;$ shRNA\#1, $160.4 \pm 7.56 \mu \mathrm{m}$. For ANOVA, $P=0.01$. For post hoc Dunnets' test, ${ }^{* *} P=0.0032$ for shRNA\#1 vs shRNA-scr; shRNA\#2, $168.8 \pm 6.98$, ${ }^{* *} P=0.0052$ for shRNA\#2 vs shRNA-scr. e Defective axon growth in Chd8 shRNA\#2 construct was rescued in neurons by co-transfected with shRNA\#2-resistant hCHD8 constructs ( $n=50$ neurons per group). Total axon length: shRNA-scr, $202.6 \pm 9.13 \mu \mathrm{m}$; shRNA\#2, $168.2 \pm 6.68 \mu \mathrm{m}$. For ANOVA, $P=0.07$. For post hoc Dunnets' test, $* * P=0.004$ for shRNA\#2 vs shRNA-scr; shRNA\#2 + hCHD8, 214.4 $\pm 6.15, P=0.32$ for shRNA\#2 + hCHD8 vs shRNA-scr. $\mathbf{f}$ Representative images of DIV7 cultured neurons transfected with GFP and Chd8 shRNA constructs as indicated. $\mathbf{g}$ Quantification of dendritic length in neurons transfected with Chd8 shRNA constructs as indicated. $n=80-100$ neurons per group. Mean dendritic length: shRNA-scr, $130.1 \pm 6.3 \mu \mathrm{m}$; shRNA\#1, $90.7 \pm 4.61 \mu \mathrm{m}$. For ANOVA, $P<0.001$. For post hoc Dunnets' test, ${ }^{* * *} P<$ 0.0001 for shRNA\#1 vs shRNA-scr; shRNA\#2, $104.5 \pm 9.53,{ }^{*} P=0.032$ for shRNA\#2 vs shRNA-scr. Total dendritic length: shRNA-scr, $694.9 \pm 42.5 \mu m ;$ shRNA\#1 is $435.9 \pm 30.6 \mu \mathrm{m}$. For ANOVA, $P=0.0007$. For post hoc Dunnets' test, ${ }^{* *} P=0.0001$ for shRNA\#1 vs shRNA-scr; shRNA\#2 is $425.3 \pm 39.2 \mu \mathrm{m}$, ${ }^{* * *} P=0.0003$ for shRNA\#2 vs shRNA-scr. $\mathbf{h}$ Quantification of dendritic complexity as measured by Sholl analysis ( $n=50-80$ neurons per group). For ANOVA, $P=0.0015$. For Bonferroni post-tests, ${ }^{*} P<0.05 ;{ }^{*} P<0.01 ;{ }^{*} P<0.001$. $\mathbf{i}$ Co-expression of the human CHD8 rescued the defective dendritic growth by the shRNA-\#2 in DIV7 neurons. $n=100-120$ neurons in each group. Data represent mean \pm SEM. For ANOVA, $P=0.0127$ (left panel); $P=0.0013$ (right panel). For post hoc Dunnett's test, ${ }^{*} P<0.05 ;{ }^{* *} P<0.01 ;{ }^{* *} P<0.001$. j Quantification of dendritic complexity as measured by Sholl analysis $(n=50-80$ neurons per group). For ANOVA, $P<0.001$. For Bonferroni post-tests, ${ }^{*} P<0.05 ;{ }^{* *} P<0.01 ;{ }^{* *} P<0.001$

\section{CHD8 is essential for neurite development in vivo}

To test whether Chd8 deficiency has effects on mouse brains in vivo, we used the shRNA\#2 construct for this experiment because of the feasibility of conducting rescue experiments as demonstrated in vitro. At P3, mouse pups electroporated with scrambled shRNA had callosal axons originating from the electroporated neurons that crossed the midline and formed and arborized dense projections to the contralateral side of cerebral cortex, and the axon bundles were restricted to the corpus callosum (CC) (Fig. 5a-c, j, k). In contrast, in mice transfected with the Chd8 shRNA\#2 construct, the axon terminals were barely visible in the contralateral cerebral cortex, indicating significantly retarded axon growth and elongation (Fig. 5d-f, j, k). Co-transfection of the shRNA\#2-resistant $h C H D 8$ construct successfully rescued these defects (Fig. 5g-k). These findings suggest that reduced expression of Chd8 in callosal projection neurons impairs axon growth and branching in vivo.

To assess the impact of Chd8 knockdown on the development of neuronal dendrites, we performed morphological analysis of the layer II/III pyramidal neurons of somatosensory cortex 1 (S1). The layer II/III pyramidal neurons of S1 constitute the main excitatory neuronal subtypes in the neocortex and typically having an apical dendrite that branches out in an apical tuft that terminates in layer I [31]. Most scrambled shRNA-transfected neurons displayed a typical polarized dendritic arbor (Fig. 6a, b). In contrast, the Chd8 shRNA significantly decreased the secondary branches and the total number and mean length of dendritic branches in neurons (Fig. 6c, d). The complexity of dendrites was also significantly decreased by $C h d 8$ shRNA constructs, revealed by Sholl analysis (Fig. 6e). These results indicated that $\mathrm{CHD} 8$ plays an essential role in neuronal morphogenesis in the mouse cerebral cortex.

\section{CHD8 deficiency impairs the migration of cortical neurons} Because of the expression of CHD8 in DCX-positive neural precursors, we examined whether its deficiency affected the radial migration of cortical neurons. The shRNA and EGFP constructs were co-electroporated into the developing mouse cortex at E14.5 using in utero electroporation (IUE) as previously described [27], and the distribution of EGFP-labeled cells in neocortex was examined at E18.5. While the majority of the EGFP-positive cells $(76.8 \pm 0.6 \%)$ migrated to the upper cortical plate (CP) when scrambled shRNA was co-expressed, only a small percentage of EGFP cells were observed in the upper CP when the Chd8 shRNA constructs were co-expressed (shRNA\#1, $10.1 \pm 1.2 \%$; shRNA\#2, $14.4 \pm 0.9 \%$; ) and the majority of labeled cells remained in the VZ/SVZ (Fig. 7a, b). Interestingly, the number of EGFP-positive cells that reached the upper $\mathrm{CP}$ was comparable between shRNA construct and scrambled controls at P3 and P7 (Fig. 7c-f). Accordingly, there are a comparable number of neurons that remained in the white matter (WM) and layers IVVI. Together, these results indicate that deficiency of Chd8 could cause a delay in radial migration of cortical neurons during early embryonic development, but this normalizes during postnatal development.

\section{Discussion}

Genetic studies have provided strong evidence supporting an etiological role for genes encoding the proteins of epigenetic machinery in ASD [10, 34]. CHD8 is one of the most prominent and repeatedly reported genes in 


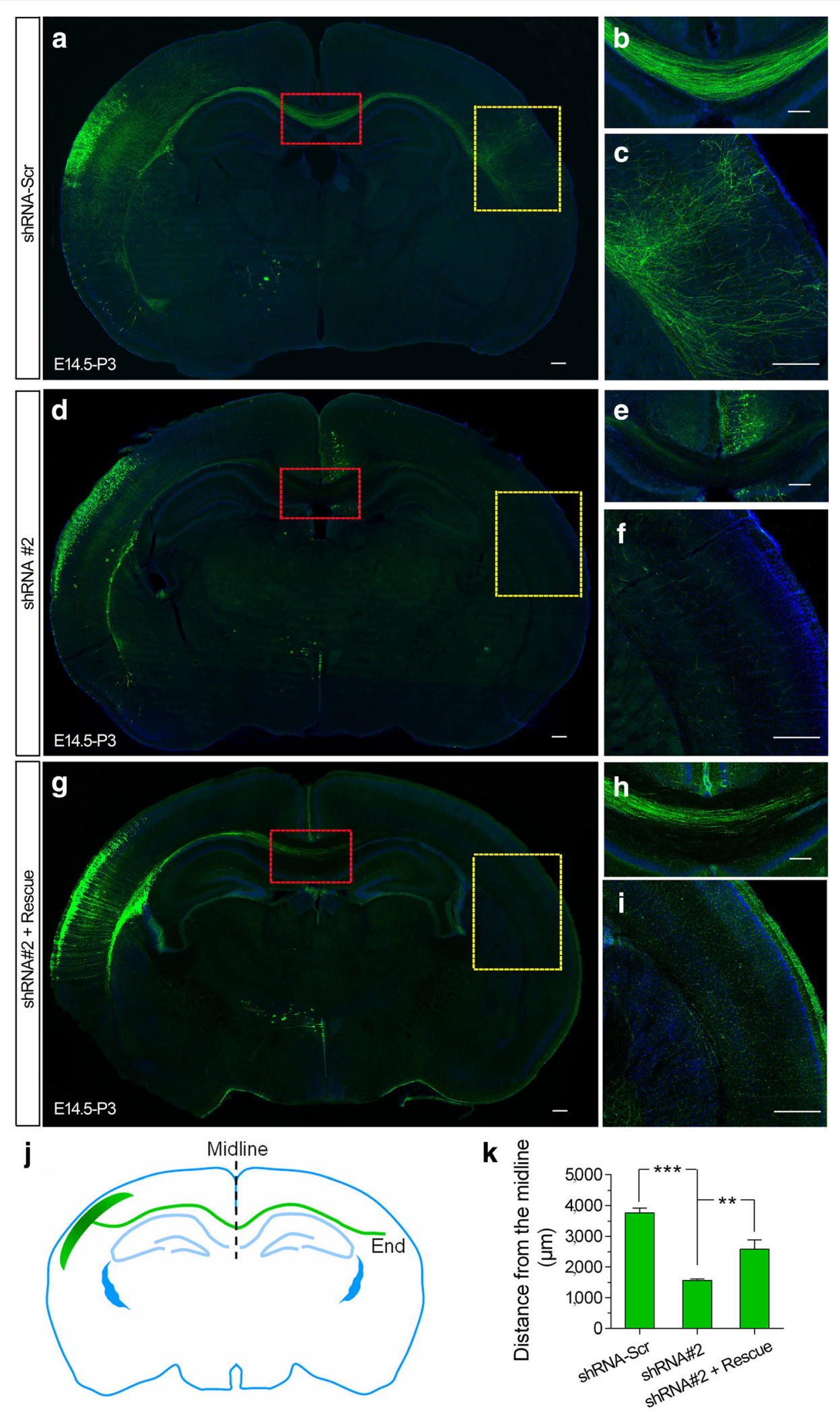

Fig. 5 (See legend on next page.) 
(See figure on previous page.)

Fig. 5 CHD8 regulates the axon growth in vivo. a-i Representative images of coronal slices of P3 mouse brains that were transfected with GFP together with indicated constructs by in utero electroporation at E14.5. High-magnification images are shown in the right. Brain slices at the level of Bregma - 1.58 mm were stained with Hoechst and GFP antibodies to visualize the callosal. Scale bar, $150 \mu \mathrm{m}(\mathbf{a}, \mathbf{d}, \mathbf{g}), 200 \mu \mathrm{m}(\mathbf{b}, \mathbf{e}, \mathbf{h})$, or $400 \mu \mathrm{m}(\mathbf{c}, \mathbf{f}, \mathbf{i})$. j A schematic for quantitative analysis of callosal axon length. The adjacent axon lengths were measured from the midline to end. $\mathbf{k}$ Quantitative analysis of callosal axon length Chd8 ShRNA\#2 construct showed significantly shorter axonal length than scramble control. The co-expression of human hCHD8 rescued the phenotypes caused by knockdown of Chd8 by shRNA\#2 construct. Distance from the midline: shRNA-scr, $3763 \pm 154.3 \mu \mathrm{m}$; shRNA\#2, $1563 \pm 47.95 \mu \mathrm{m}$. ${ }^{* * *} P<0.0001$ shRNA\#2 vs shRNA-scr; shRNA\#-hCHD8, $2575 \pm 307.2 \mu \mathrm{m} .{ }^{* *} P=0.0021$ shRNA\#2-hCHD8 vs shRNA-scr. Results are shown as mean \pm SEM. $n=4$ in each group. For ANOVA, $P=0.0016$. For Bonferroni post-tests, ${ }^{* *} P<0.01 ;{ }^{* *} P<0.001$

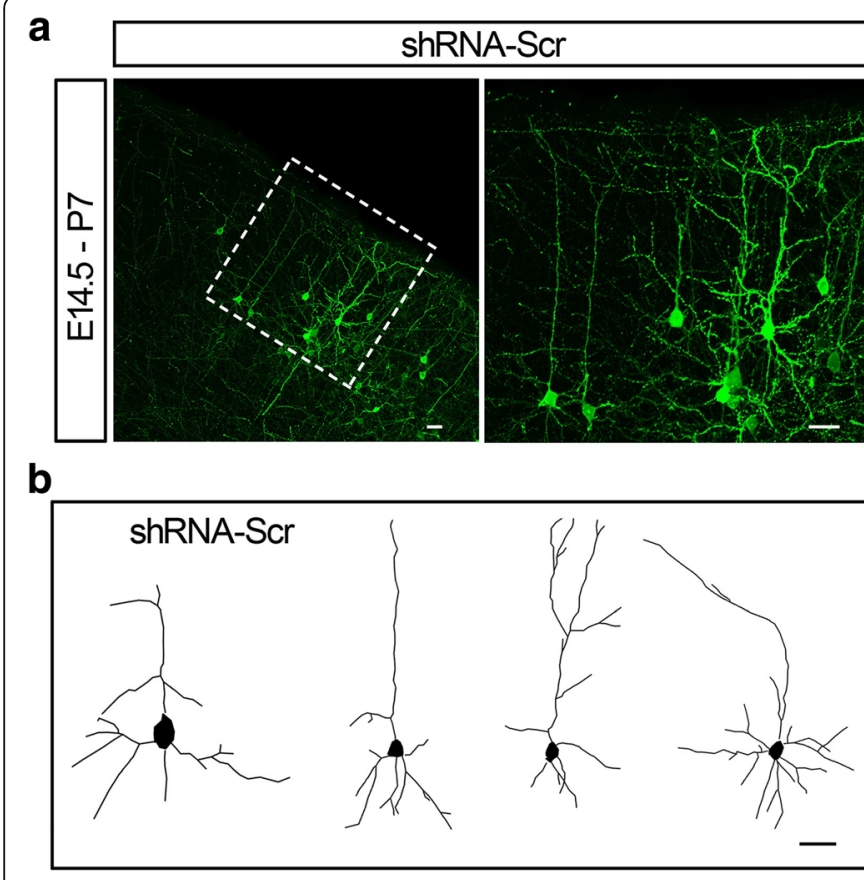

C

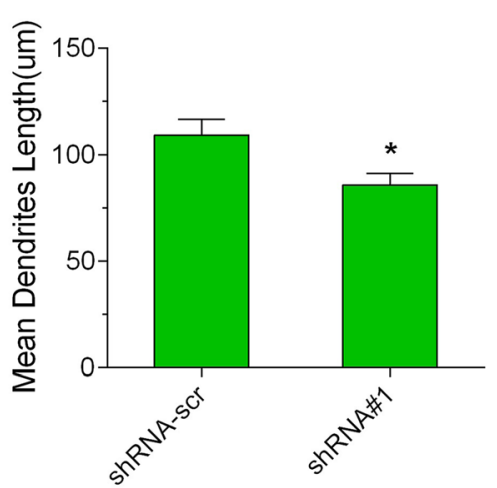

d

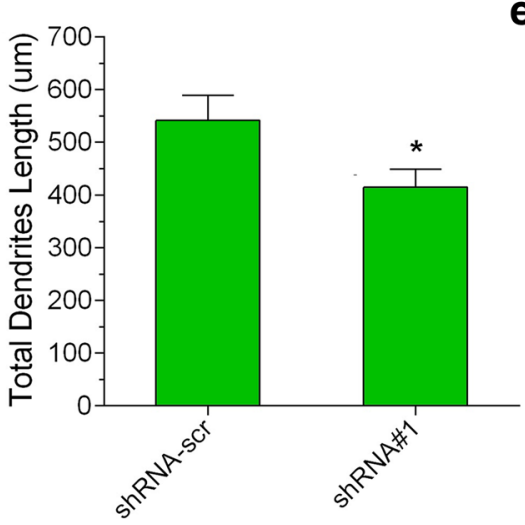

shRNA-\#1
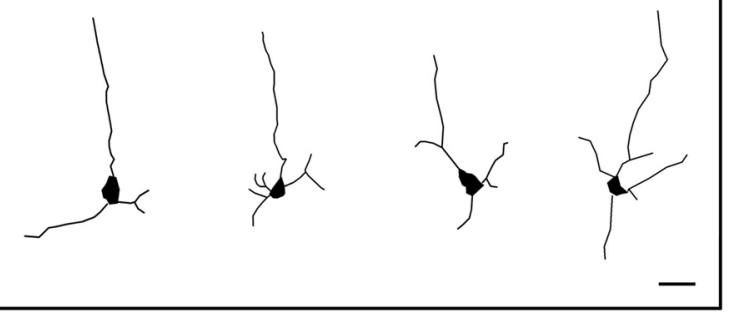

e

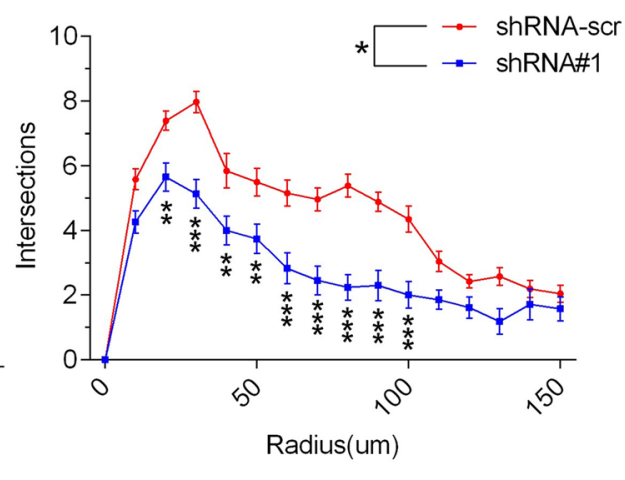

Fig. 6 CHD8 is required for dendrite growth in vivo. a Representative images of coronal slices of P7 mouse brains that were transfected with GFP together with indicated constructs by in utero electroporation at E14.5. Transfected cells were visualized by staining coronal slices with GFP antibody. In each image pair, the right image is from the boxed region of the left image. Scale bar, $100 \mu \mathrm{m}$. b Neurolucida tracings of representative layer I/III pyramidal neurons, from experiment shown in $\mathbf{a}$. Scale bar, $50 \mu \mathrm{m}$. c-e Quantitative analysis of dendrite length and dendrite complexity measured from Neurolucida tracings. Mean dendritic length: shRNA-scr, $109.2 \pm 7.5 \mu \mathrm{m}$; shRNA\#1, $85.9 \pm 5.59 \mu \mathrm{m},{ }^{*} P=0.015$, shRNA\#1 vs shRNA-scr. Total dendritic length: shRNA-scr, $541.6 \pm 47.52 \mu \mathrm{m}$; shRNA\#1, $415.233 .89 \mu \mathrm{m},{ }^{*} P=0.0332$, shRNA\#1 vs shRNA-scr. Greater than 70 neurons were examined in each group from at least three independent experiments. Results are presented as the mean \pm SEM. ${ }^{*} P<0.05 ;{ }^{* *} P<0.01 ;{ }^{* *} P<0.001$; one-way ANOVA post Dunnett's test 


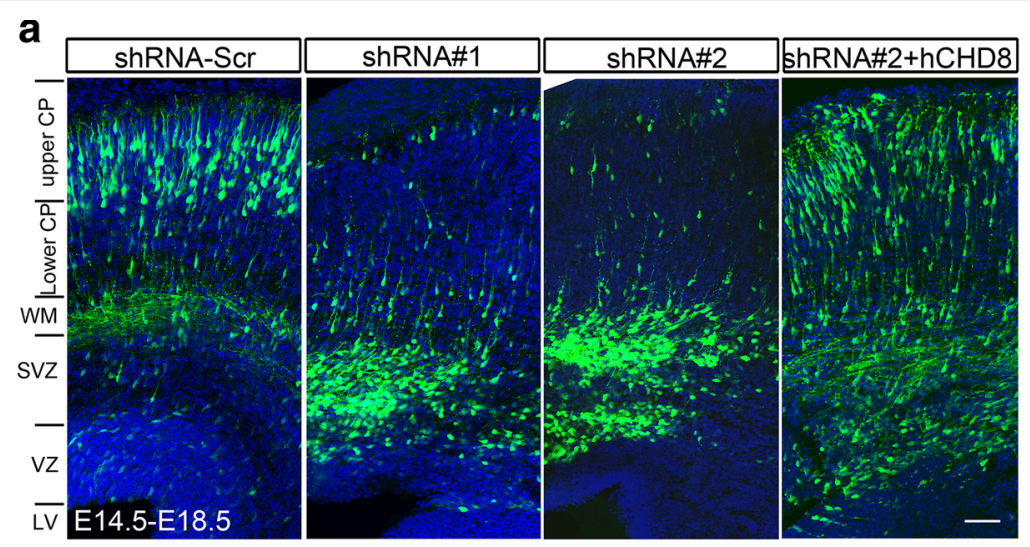

b $\quad \stackrel{\text { 心 }}{\bar{\Phi}} 100]$ shRNA-Scr shRNA\#1 shRNA\#2 shRNA\#2+hCHD8

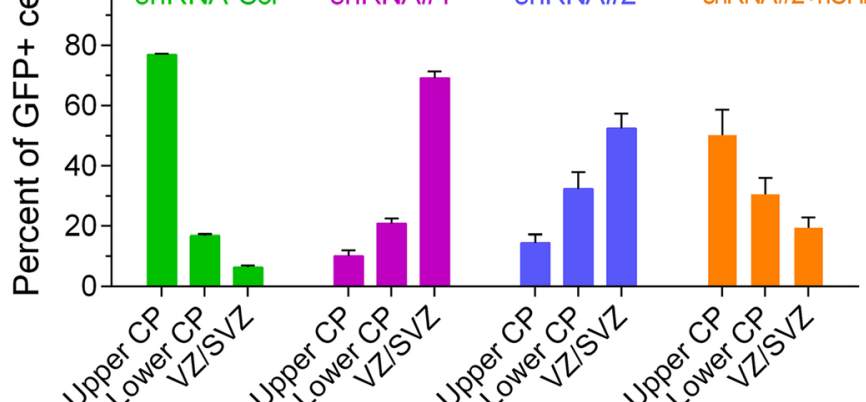

C

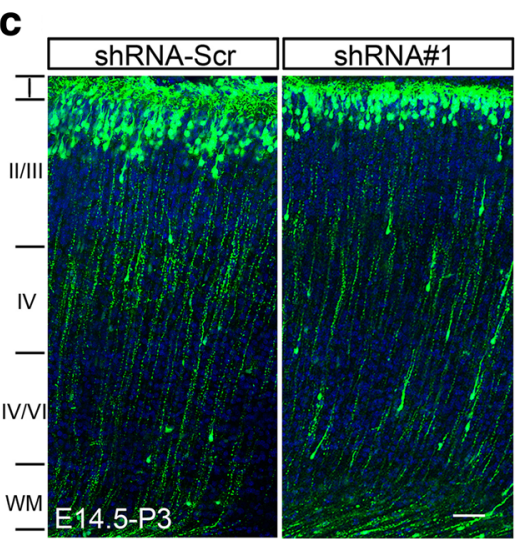

d
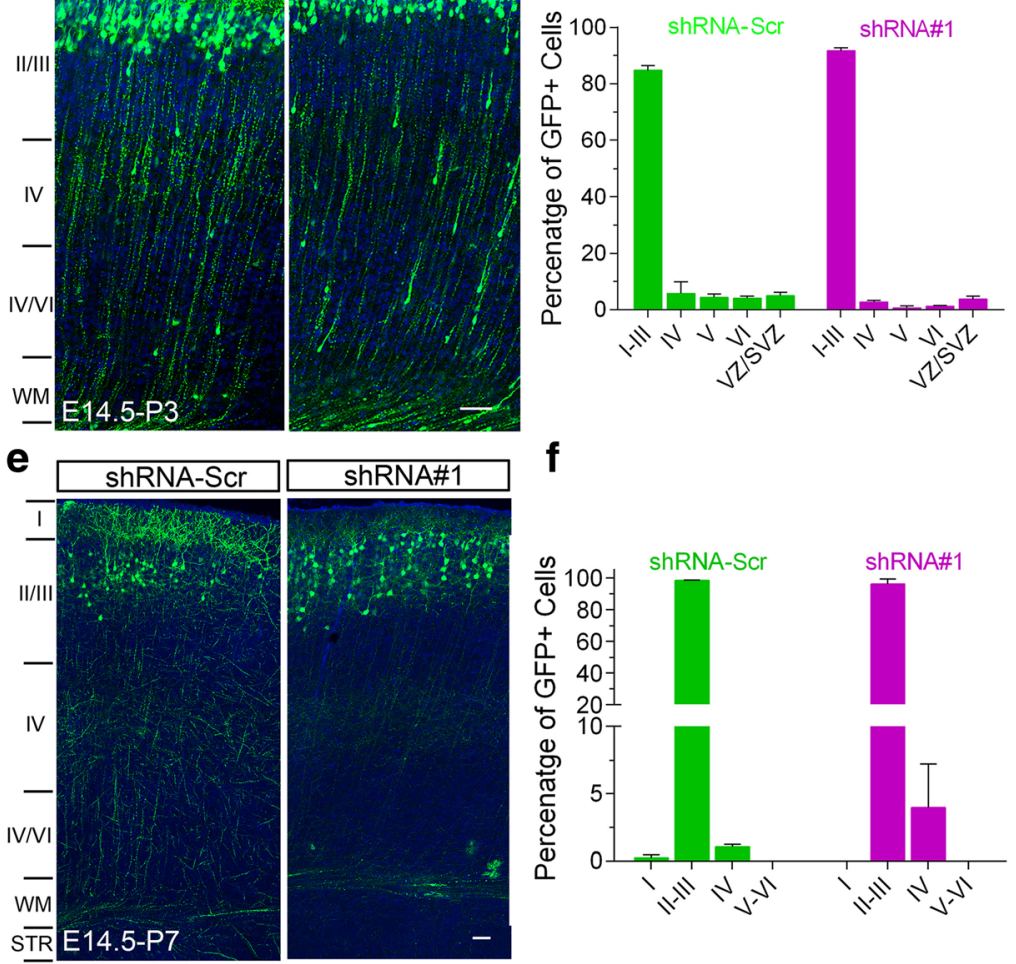

$f$

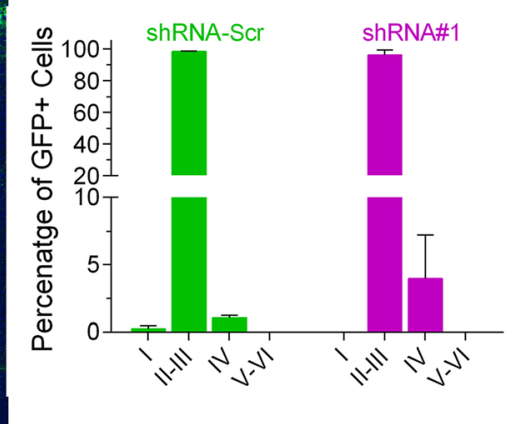

Fig. 7 (See legend on next page.) 
(See figure on previous page.)

Fig. 7 Chd8 knockdown delays neuronal migration in vivo. a Representative images of coronal slices of E18.5 mouse brains that were transfected with GFP together with indicated Chd8 constructs by in utero electroporation at E14.5. At E18.5, cortical neurons transfected with Chd8-shRNA constructs were misplaced in the VZ/SVZ instead of CP. Transfected cells were visualized by staining coronal slices with GFP antibody. Scale bar $200 \mu \mathrm{m}$. b Quantitative analysis of the distribution of cortical neurons transfected with different constructs across three different zones in the somatosensory cortex: upper $\mathrm{cp}$, lower $\mathrm{cp}, \mathrm{VZ} / \mathrm{SVZ}$. Results are mean \pm SEM from 6 to 12 sections (one per mouse) for each experiment. c, d By P3, cortical neurons migrated normally from the SVZ into the cortex in both control and Chd8 RNAi-transfected brains. Scale bar, $120 \mu \mathrm{m}$. e, f At P7, most transfected neurons were located in the layers II/III in both control and Chd8 shRNA-transfected brains. Scale bar, $200 \mu \mathrm{m}$

this class [13]. In contrast to the well-characterized synaptic genes that are also strongly implicated in ASD, the molecular pathogenesis of ASD caused by deficiency of epigenetic machinery proteins such as $C H D 8$ remains to be thoroughly investigated. Through studies of $C h d 8$ deficiency in cultured rodent neurons or mutant mice by different experimental approaches, several groups have provided initial evidence supporting a causal link between a deficiency of CHD8 and neural cell proliferation, synaptic function, myelination, and ASD-like behaviors. The major findings from these studies and the current study are summarized in Table $1[18,20-25,35,36]$. The results among these studies are not always consistent; in some cases, opposite findings are reported. For example, the decreased proliferation of neural progenitor cells is associated with Chd8 deficiency using RNAi by in utero electroporation but the increased proliferation was reported in mice with germline mutation. Interestingly, a recent study of a new line of $C h d 8$ mutant mice reports sexually dimorphic phenotypes at molecular, synaptic function, and behavioral levels [24]. Another report also finds that $C h d 8$ deficiency, selectively in oligodendrocytes but not in neurons, results in myelination defects in mice. Similarly, different ASD-related behavioral phenotypes are also observed among different lines of Chd8 mutant mice. Unfortunately, behavioral phenotypes have not been examined in oligodendrocytespecific $C h d 8$ deficiency mice. Whether these discrepancies are due to different Chd8 mutations in these lines of mutant mice or other experimental procedure-related issues are not immediately clear. Future studies of performing the experiments in parallel in different lines Chd8 mutant mice are warranted.

In this study, we have shown that CHD8 is expressed at high level in both NeuN-positive mature neurons and parvalbumin-positive interneurons and to a lesser extent in GFAP-positive astrocytes in human cerebral cortex. A previous study has found that the peak expression of CHD8 is between 13 and 19 weeks in the dorsolateral prefrontal cortex and 10-13 weeks of medial prefrontal cortex in humans [18]. In the developing mouse brain, we find that Chd8/ CHD8 expression peaks around embryonic days 16-18 and decreases to much lower levels by P21 by both mRNA and protein analyses. This finding is largely consistent with the reports of the development-specific expression of CHD8 in previous studies $[18,20,22]$. However, there are differences in the experimental designs among these studies. In our study, the Chd8 expression study by real-time RT-PCR, RNA in situ hybridization, and western blot are performed in tissues from E16 day embryos to adult brains. In study by Nishiyama et al., the expression is examined by western blot and whole mount in situ in cells or tissues from embryonic stem (ES) cells as well as from E7.5 day embryos to adult mice [20]. The expression is high in ES and early embryonic stage, but a definitive peak is not seen. In other study by Platt et al. [22], real-time RT-PCR, western blot, and RNA in situ hybridization are used to examine the Chd8 expression in brain tissues from E10 day embryos to adult mice. The highest expression is seen around E10-11 day embryos. In the study that the expression is examined in brain tissues from E12 to P2, the highest expression is at E12 [18]. With the caveats in the experimental designs, it is possible that the peak expression of Chd8 is before E7 day because homozygous $C h d 8$ mutant are arrested before gastrulation because of massive apoptosis [20].

Consistent with previous report [18], we have also shown the evidence supporting the role of CHD8 in dendrite development of pyramidal neurons. The loss of CHD8 inhibits dendritic outgrowth and branch formation. In contrast to other reports, we have shown for the first time from both in vitro and in vivo studies that deficiency of CHD8 in developing mouse neurons inhibits axon growth and branch formation and results in a disruption of callosal axon projections to the contralateral cortex. The effect of CHD8 deficiency on the growth of axons is consistent with the report of dysregulation of genes implicated in axonal development in IPSC-derived neurons from human CHD8 patients [36, 37]. Together, our data demonstrate that CHD8 is important for normal dendritic and axonal development and that dysregulation of the process may contribute abnormal neuronal connectivity.

The peak expression in early and middle fetal development suggests a functional role of CHD8 in cortical development. Indeed, we found that $C h d 8$ knockdown results in a significant delayed migration of newborn cortical neurons examined at E18.5. This is opposite to the enhanced migration reported by Durak et al. using the similar approach but at different time points during the fetal development [18]. We performed in utero electroporation for Chd8 knockdown at E14.5 and analyzed 
Table 1 Summary of the findings from the current study and relevant literature

\begin{tabular}{ll}
\hline Reference(s) & Endogenous CHD8 \\
expression data relating \\
to the current study
\end{tabular}

Durak et al. [18]

Nishiyama et al. [20] and Katayama et al. [21]

Platt et al. [22]

Zhao et al. [25]

Gompers et al. [35]
Mice (brain lysates): expression peaks at $\mathrm{E} 12$, then decreases during embryonic development to P2 by qPCR

Human (DFC and MFC): expression peaks during early-mid fetal development and decreases from late fetal development to childhood by $\mathrm{qPCR}$

Mice (whole embryos): CHD8 was expressed in ES cells ( E3.5), E8.5 embryos, E12.5 embryos, E16.5 embryos, and to a lesser extent in newborn pups by western blotting

Mice (whole brains): expression profile from E10-P0, adult. Expression is highest at E10 and decreases over development by western blotting

Mice (adult brain sections, somatosensory cortex): CHD8 shows nuclear localization and co-expresses with NeuN, PV, CNP1, and GFAP by immunostaining

Mice (P14 white matter tracts): CHD8 is expressed in oligodendrocytes and to a lesser extent in GFAP+ astrocytes by immunostaining

Human (cerebellum): CHD8 expression in Sox 10+ oligodendrocytes by immunostaining Mice (P14 cortical sections): CHD8 is expressed in NeuN+ neurons but not clearly in GFAP+ astroctyes or Iba1+ microglia by immunostaining

Expression analysis was not reported for different cell types or developmental time points

Model system(s) and

method(s) used for disrupting CHD8 expression

Findings caused by disrupting CHD8 expression relating to the current study

- Mice (in vitro) - cultured neurons transfected with Chd8 shRNA constructs

- Mice (in vivo) - in utero electroporation at E14.5 with Chd8 shRNA constructs

- Decreased axon length (both in vitro and in vivo)

- Reduced dendritic complexity (both in vitro and in vivo)

- Delayed neuronal migration (higher percentage of GFP+ cells in VZ/SVZ instead of (P) at E18.5 (in vivo), which normalized by $\mathrm{P} 3$

Mice-in utero electroporation at E13 (for neuronal proliferation/ migration studies) or E15 (for dendritic arborization studies) with Chd8 shRNA constructs

Mice - two lines of germline haploinsufficient mice were generated (replacing 9 exons with loxP-neo cassette, or $\Delta$ exons 11-13, disrupting only the long protein isoform)

Mice-germline haploinsufficient mice were generated by CRISPR/Cas9 introducing a 7 nucleotide deletion in exon 1, which disrupted the expression of both CHD8 isoforms

Conditional Chd8 knockout mice (loxP sites surrounding exon 4) crossed with oligodendrocyte-specific Cre line

Mice-germline Chd8 haploinsufficient mice were generated (deletion of exon 5)
- Increased neuronal migration (more GFP+ cells in CP instead of VZ/SVZ) at E16, accompanied by reduced proliferation, increased cell cycle exit, reduced mitotic activity, and premature Tuj1 expression

- Decreased dendritic arborization in upper cortical neurons from 5-month-old mice

- CHD8 mediates cortical neurogenesis via transcriptional regulation of cell cycle and Wnt signaling

- Homozygous mutants show massive apoptosis at E7.5 and lethality

- At E14.5, haploinsufficient mice showed increased expression of early-fetal genes and decreased expression of mid-fetal genes

- Normal lamination and specification of neuronal cell types at P21

- No difference in number of cortical progenitor cells or cell cycle length at E15.5

- Homozygous conditional knockout mice show lethality by P21 and myelination defects

- Homozygous conditional knockout mice show reduced proliferation of oligodendrocyte precursor cells in P1 spinal cord

- Dual requirement of CHD8 for chromatin landscape establishment and histone methyltransferase recruitment to promote CNS myelination and repair

- Increased proliferation of neuronal progenitors at E14.5

- No gross lamination errors by PO and P7 
Table 1 Summary of the findings from the current study and relevant literature (Continued)

\begin{tabular}{|c|c|c|c|}
\hline Reference(s) & $\begin{array}{l}\text { Endogenous CHD8 } \\
\text { expression data relating } \\
\text { to the current study }\end{array}$ & $\begin{array}{l}\text { Model system(s) and } \\
\text { method(s) used for } \\
\text { disrupting CHD8 expression }\end{array}$ & $\begin{array}{l}\text { Findings caused by disrupting } \\
\text { CHD8 expression relating to the } \\
\text { current study }\end{array}$ \\
\hline $\begin{array}{l}\text { Wang et al. [36] } \\
\text { CRISPR/Cas9-mediated } \\
\text { heterozygous } \\
\text { knockout of the } \\
\text { autism gene CHD8 } \\
\text { and characterization } \\
\text { of its transcriptional } \\
\text { networks in } \\
\text { neurodevelopment }\end{array}$ & N/A & $\begin{array}{l}\text { CRISPR/Cas9-mediated heterozygous } \\
\text { knockout of CHD8 in iPSCs }\end{array}$ & $\begin{array}{l}\text { - Genes involved in cell cycle, } \\
\text { neuronal differentiation, and in } \\
\text { neuronal projection development } \\
\text { are dysregulated }\end{array}$ \\
\hline Suetterlin et al. [23] & N/A & $\begin{array}{l}\text { Chd8+/- mice } \\
\text { (loxP sites on exon 3) } \\
\text { crossed } \beta \text {-actinCre line }\end{array}$ & $\begin{array}{l}\text { - Chd8 heterozygous mice display } \\
\text { increased total brain volume and } \\
\text { showed volumetric increased of } \\
\text { several brain regions, including } \\
\text { cortical areas, hippocampus and } \\
\text { parts of the cerebellum by high- } \\
\text { solution MRI } \\
\text { - CHD8 controls the expression of } \\
\text { ASD-associated axon guidance } \\
\text { genes in the early postnatal } \\
\text { neocortex }\end{array}$ \\
\hline Jung et al. [24] & $\begin{array}{l}\text { In both males and females, CHD8 } \\
\text { protein was more abundant in } \\
\text { the brain relative to other tissues, } \\
\text { at embryonic stages relative to } \\
\text { postnatal stages, and in non-crude } \\
\text { synaptosomal fractions }\end{array}$ & $\begin{array}{l}\text { Chd8+/N2373 K mice carrying } \\
\text { a heterozygous Chd8 } \\
\text { frame-shift mutation }\end{array}$ & $\begin{array}{l}\text { - Distinct c-fos signals in male and } \\
\text { female Chd } 8^{+/ N 2373 \mathrm{~K}} \text { brains under } \\
\text { baseline and maternal-separation } \\
\text { conditions } \\
\text { - Opposite changes in inhibitory } \\
\text { synaptic transmission in the male } \\
\text { and female Chd } 8^{+/ N 2373 \mathrm{~K}} \\
\text { hippocampus }\end{array}$ \\
\hline
\end{tabular}

the cell migration at E18.5 while Durak et al. performed the in utero electroporation at E14 and analyzed at E16. Whether the different timing of CHD8 deficiency is responsible for the observed phenotypic differences remains to be determined. Because transcriptional regulation implicated in cortical development is dynamic and epigenetically modulated [38], it is also conceivable that CHD8 may have different roles at the different stages of fetal brain development. Interestingly, the delayed neuronal migration associated with knockdown of Chd8 in our study is recovered at P3 and P7. This may suggest a catch-up period of the CHD8-deficient neurons after E18.5 days. Taken together, our findings support that CHD8 plays a critical role in migration of mitotic neurons as well as both dendritic and axonal growth in neocortex.

Human patients with $C H D 8$ mutations present with typical autistic behaviors and comorbidities including social deficits and communication difficulties, repetitive behaviors and interests, and cognitive delays [8, 13]. However, the findings from existing studies in model organisms have not provided a clear mechanistic link between genetic defects and clinical presentations [13, 21, $22,25,35,39]$. One of the notable features in some of the patients with $C H D 8$ mutations is relatively enlarged brain (macrocephaly) [13]. This feature is consistent with the findings of enlarged brains in a sub-set of idiopathic ASD cases during early postnatal brain development. Germline mutations of Chd8 in zebrafish and mice have recapitulated the feature of enlarged brain size [13, 21, 22, 25, 35]. Accordingly, increased proliferation of neuronal progenitor cells and dysregulation of expression cell cycle genes are associated with germline line Chd8 mutation [35]. Whether this is the underlying mechanism for macrocephaly associated with CHD8 mutations and whether it is generalizable to the macrocephaly in other idiopathic ASD cases remain to be investigated. Notably, massive apoptosis is observed in E5.5 embryos carrying germline Chd8 homozygous mutation [20] and somatic knockdown of Chd8 by RNAi using in utero electroporation results in a decrease proliferation of neural progenitors [18]. These observations may indicate a different role of CHD8 at different developmental stages. More importantly, a critical question for future investigation is whether the cellular defects and enlarged brain size are responsible for ASD-like behaviors observed in Chd8 heterozygous mutant animals.

In summary, CHD8 protein is highly enriched in neurons of developing neocortex in both human and mice and plays a critical role in regulating neuronal migration as well as growth of neurites. Our findings suggest that CHD8 mutations in humans may also result in defects of 
neuronal migration and morphogenesis defects during a crucial stage of brain development and this impaired process may contribute to the pathophysiology of ASD.

\section{Additional file}

Additional file 1: Validation of rescued constructs against shRNAmediated knockdown of mouse Chd8 in transfected neurons in vitro. (JPG $92 \mathrm{~kb})$

\section{Abbreviations}

ASD: Autism spectrum disorder; CC: Corpus callosum; CHD8: Chromodomain helicase DNA-binding protein 8; CP: Cortical plate; hCHD8: Human CHD8 protein; IHC: Immunohistochemistry; IUE: In utero electroporation; qRTPCR: Quantitative real-time RNA; SP: Sub-plate; SVZ: Subventricular zone; VZ: The ventricular zone

\section{Funding}

This work was supported by the National Science Foundation of China [81701496 to QX, 81371270 to XX]; Shanghai Municipal Science and Technology Commission [15411967900 to QX]; and the National Institute of Health [MH098114, HD087795, MH104316 to YHJ].

\section{Availability of data and materials}

The datasets used and analyzed during the current study are available from the corresponding author on reasonable request.

\section{Authors' contributions}

$\mathrm{QX}$ and $\mathrm{YHJ}$ conceived the project. QX and $\mathrm{YYL}$ did major experiments and analyzed the data. QX, YYL, XMW, GHT, XX, SWH, and YHJ interpreted the data and wrote the manuscript. All authors read and approved the final manuscript.

\section{Ethics approval}

Animals: The use of mice was in accordance with guidelines and Institutional Animal Care and Use Committee-approved protocols both at Children's Hospital of Fudan University ethics approval ID: 2015-87 and Duke University. Human postmortem brain tissues: The use of archived human postmortem brain tissues is approved by Institute Review Board at Duke University.

\section{Consent for publication}

Not applicable

\section{Competing interests}

The authors declare that they have no competing interests.

\section{Publisher's Note}

Springer Nature remains neutral with regard to jurisdictional claims in published maps and institutional affiliations.

\section{Author details}

'Department of Child Health Care, Children's Hospital of Fudan University, Shanghai 201102, China. ${ }^{2}$ Guangxi Key Laboratory of Regenerative Medicine \& Guangxi Collaborative Innovation Center for Biomedicine, School of Preclinical Medicine, Guangxi Medical University, Nanning 530021, Guangxi, China. ${ }^{3}$ Department of Pediatrics, Duke University School of Medicine, Durham 27710, NC, USA. ${ }^{4}$ Department of Neurobiology, Duke University School of Medicine, Durham 27710, NC, USA. ${ }^{5}$ Institute of Neuroscience \& State Key Laboratory of Neuroscience, CAS Center for Excellence in Brain Science and Intelligence Technology, Shanghai Institutes for Biological Sciences, Chinese Academy of Sciences, Shanghai 200031, China. ${ }^{6}$ University of Chinese Academy of Sciences, Beijing 100049, China. Program in Genetics and Genomics, Duke University School of Medicine, Durham 27710, NC, USA. ${ }^{8}$ Cellular Molecular Biology, Duke University School of Medicine, Durham 27710, NC, USA
Received: 11 August 2018 Accepted: 15 November 2018

Published online: 19 December 2018

\section{References}

1. Miles JH. Autism spectrum disorders--a genetics review. Genet Med. 2011; 13(4):278-94.

2. Watts TJ. The pathogenesis of autism. Clin Med Pathol. 2008;1:99-103.

3. O'Roak BJ, et al. Exome sequencing in sporadic autism spectrum disorders identifies severe de novo mutations. Nat Genet. 2011:43(6):585-9.

4. lossifov I, et al. De novo gene disruptions in children on the autistic spectrum. Neuron. 2012;74(2):285-99.

5. Michaelson JJ, et al. Whole-genome sequencing in autism identifies hot spots for de novo germline mutation. Cell. 2012;151(7):1431-42.

6. Neale BM, et al. Patterns and rates of exonic de novo mutations in autism spectrum disorders. Nature. 2012:485(7397):242-5.

7. Sanders SJ, et al. De novo mutations revealed by whole-exome sequencing are strongly associated with autism. Nature. 2012;485(7397):237-41.

8. O'Roak BJ, et al. Sporadic autism exomes reveal a highly interconnected protein network of de novo mutations. Nature. 2012;485(7397):246-50.

9. Jiang $\mathrm{YH}$, et al. Detection of clinically relevant genetic variants in autism spectrum disorder by whole-genome sequencing. Am J Hum Genet. 2013; 93(2):249-63.

10. De Rubeis $\mathrm{S}$, et al. Synaptic, transcriptional and chromatin genes disrupted in autism. Nature. 2014:515(7526):209-15.

11. Iossifov I, et al. The contribution of de novo coding mutations to autism spectrum disorder. Nature. 2014;515(7526):216-21.

12. Krumm N, et al. Excess of rare, inherited truncating mutations in autism. Nat Genet. 2015;47(6):582-8

13. Bernier $\mathrm{R}$, et al. Disruptive CHD8 mutations define a subtype of autism early in development. Cell. 2014;158(2):263-76.

14. O'Roak BJ, et al. Multiplex targeted sequencing identifies recurrently mutated genes in autism spectrum disorders. Science. 2012;338(6114): $1619-22$

15. Marfella CG, Imbalzano AN. The Chd family of chromatin remodelers. Mutat Res. 2007:618(1-2):30-40.

16. Okerlund ND, Cheyette BN. Synaptic Wnt signaling - a contributor to major psychiatric disorders? J Neurodev Disord. 2011;3(2):162-74.

17. Sakamoto I, et al. A novel beta-catenin-binding protein inhibits betacatenin-dependent Tcf activation and axis formation. J Biol Chem. 2000; 275(42):32871-8

18. Durak $\mathrm{O}$, et al. Chd8 mediates cortical neurogenesis via transcriptional regulation of cell cycle and Wnt signaling. Nat Neurosci. 2016;19(11):1477-88.

19. Nishiyama M, et al. CHD8 suppresses p53-mediated apoptosis through histone $\mathrm{H} 1$ recruitment during early embryogenesis. Nat Cell Biol. 2009; 11(2):172-82.

20. Nishiyama M, et al. Early embryonic death in mice lacking the beta-cateninbinding protein Duplin. Mol Cell Biol. 2004;24(19):8386-94.

21. Katayama $Y$, et al. CHD8 haploinsufficiency results in autistic-like phenotypes in mice. Nature. 2016;537(7622):675-9.

22. Platt RJ, et al. Chd8 mutation leads to autistic-like behaviors and impaired striatal circuits. Cell Rep. 2017;19(2):335-50.

23. Suetterlin $\mathrm{P}$, et al. Altered neocortical gene expression, brain overgrowth and functional over-connectivity in Chd8 haploinsufficient mice. Cereb Cortex. 2018;28(6):2192-206.

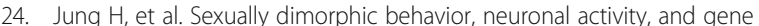
expression in Chd8-mutant mice. Nat Neurosci. 2018;21(9):1218-28.

25. Zhao $\mathrm{C}$, et al. Dual requirement of CHD8 for chromatin landscape establishment and histone methyltransferase recruitment to promote CNS myelination and repair. Dev Cell. 2018:45(6):753-68 e8.

26. Guo SL, et al. Serum inducible kinase is a positive regulator of cortical dendrite development and is required for BDNF-promoted dendritic arborization. Cell Res. 2012;22(2):387-98.

27. Miao S, et al. The Angelman syndrome protein Ube3a is required for polarized dendrite morphogenesis in pyramidal neurons. J Neurosci. 2013; 33(1):327-33.

28. Li S, et al. TORC1 regulates activity-dependent CREB-target gene transcription and dendritic growth of developing cortical neurons. J Neurosci. 2009:29(8):2334-43.

29. Anagnostou E, Taylor MJ. Review of neuroimaging in autism spectrum disorders: what have we learned and where we go from here. Mol Autism. 2011;2(1):4. 
30. Di Martino A, et al. The autism brain imaging data exchange: towards a large-scale evaluation of the intrinsic brain architecture in autism. Mol Psychiatry. 2014;19(6):659-67.

31. Penzes $P$, et al. Dendritic spine pathology in neuropsychiatric disorders. Nat Neurosci. 2011;14(3):285-93.

32. Hulbert SW, Jiang YH. Cellular and circuitry bases of autism: lessons learned from the temporospatial manipulation of autism genes in the brain. Neurosci Bull. 2017;33(2):205-18.

33. Hulbert JC, Henson RN, Anderson MC. Inducing amnesia through systemic suppression. Nat Commun. 2016;7:11003.

34. Jeremy Willsey A, State MW. Autism spectrum disorders: from genes to neurobiology. Curr Opin Neurobiol. 2015;30C:92-9.

35. Gompers AL, et al. Germline Chd8 haploinsufficiency alters brain development in mouse. Nat Neurosci. 2017;20(8):1062-73.

36. Wang P, et al. CRISPR/Cas9-mediated heterozygous knockout of the autism gene CHD8 and characterization of its transcriptional networks in neurodevelopment. Mol Autism. 2015;6:55.

37. Sugathan A, et al. CHD8 regulates neurodevelopmental pathways associated with autism spectrum disorder in neural progenitors. Proc Natl Acad Sci U S A. 2014;111(42):E4468-77.

38. de la Torre-Ubieta $\mathrm{L}$, et al. The dynamic landscape of open chromatin during human cortical neurogenesis. Cell. 2018;172(1-2):289-304 e18.

39. Wang P, et al. CRISPR/Cas9-mediated heterozygous knockout of the autism gene CHD8 and characterization of its transcriptional networks in cerebral organoids derived from iPS cells. Mol Autism. 2017:8:11.

Ready to submit your research? Choose BMC and benefit from:

- fast, convenient online submission

- thorough peer review by experienced researchers in your field

- rapid publication on acceptance

- support for research data, including large and complex data types

- gold Open Access which fosters wider collaboration and increased citations

- maximum visibility for your research: over $100 \mathrm{M}$ website views per year

At $\mathrm{BMC}$, research is always in progress.

Learn more biomedcentral.com/submissions 